\title{
Thromboembolic Disease Due to Thermolabile Conformational Changes of Antithrombin Rouen-VI (187 Asn $\rightarrow$ Asp)
}

\author{
David Bruce, David J. Perry, Jeanne-Yvonne Borg, ${ }^{\star}$ Robin W. Carrell, and Mark R. Wardell \\ Department of Haematology, University of Cambridge, MRC Centre, Cambridge CB2 2QH, United Kingdom; and *Laboratoire \\ d'Hématologie, Hôpital Charles-Nicolle, 76031 Rouen Cedex, France
}

\begin{abstract}
A new variant of antithrombin (Rouen-VI, 187 Asn $\rightarrow$ Asp) with increased heparin affinity was shown to have normal inhibitory activity which decreased slowly at $4^{\circ} \mathrm{C}$ and rapidly at $41^{\circ} \mathrm{C}$. On electrophoresis the freshly isolated variant had an anodal shift relative to native antithrombin due to the mutation. A further anodal transition occurred after either prolonged storage at $4^{\circ} \mathrm{C}$ or incubation at $41^{\circ} \mathrm{C}$ due to the formation of a new inactive uncleaved component with properties characteristic of L-form (latent) antithrombin. At the same time, polymerization also occurred with a predominance of di-, tri-, and tetra-mers. These findings fit with the observed mutation of the conserved asparagine (187) in the F-helix destabilizing the underlying A-sheet of the molecule. Evidence of $\mathbf{A}$-sheet perturbation is provided by the increased rate of peptide insertion into the $A$-sheet and by the decreased vulnerability of the reactive loop to proteolysis. The spontaneous formation of both L-antithrombin and polymers is consistent with our crystal structure of intact antithrombin where $L$-form and active antithrombin are linked together as dimers. The nature of this linkage favors a mechanism of polymerization whereby the opening of the A-sheet, to give incorporation of the reactive center loop, is accompanied by the bonding of the loop of one molecule to the $\mathrm{C}$-sheet of the next. The accelerated lability of antithrombin Rouen-VI at 41 versus $37^{\circ} \mathrm{C}$ provides an explanation for the clinical observation that episodes of thrombosis were preceded by unrelated pyrexias. (J. Clin. Invest. 1994. 94:2265-2274.) Key words: latentantithrombin - serpins - loop-sheet polymerization • antithrombin III • protein conformation
\end{abstract}

\section{Introduction}

Antithrombin (formerly antithrombin III) is the major inhibitor of coagulation in human plasma $(1,2)$ and is a member of the

This study was presented at the proceedings of the Joint Meeting of British-French Societies of Thrombosis and Haemostasis in Bordeaux, France on 25 November 1993 and was published in abstract form (1994. Nouvelle Révue Française d'Hématologie. 36:267).

Address correspondence to Dr. Mark R. Wardell, Department of Haematology, University of Cambridge, MRC Centre, Hills Road, Cambridge CB2 $2 \mathrm{QH}$, United Kingdom.

Received for publication 25 February 1994 and in revised form 20 June 1994.

J. Clin. Invest.

(C) The American Society for Clinical Investigation, Inc. $0021-9738 / 94 / 12 / 2265 / 10 \quad \$ 2.00$

Volume 94, December 1994, 2265-2274 serpin family of serine protease inhibitors (3). The serpins have the novel feature of a reactive site situated on a mobile peptide loop extending from 15 residues $\left(P_{15}\right)$ amino-terminal to 5 residues $\left(\mathrm{P}_{5}{ }^{\prime}\right)$ carboxy-terminal of the reactive center residue $P_{1}$. This loop can adopt a variety of conformations that vary in the degree of insertion of the loop into the main $\beta$-pleated sheet of the molecule (4). The mobility of the loop in the serpins is illustrated in Fig. 1, which shows in $a$ the helical loop of the noninhibitor ovalbumin (5) and in $b$ the partially inserted loop of active antithrombin $(6,7)$. A structure intermediate to these has also been determined recently for active $\alpha_{1}$-antichymotryp$\sin (8)$ which has a loop in the form of a partially opened helix without any insertion into the A-sheet. The conclusion (7) at this stage is that formation of a stable inhibitor protease complex requires exposure of the reactive center together with a flexibility of the loop to allow partial insertion into the A-sheet. Complete insertion of the loop into the sheet with an accompanying loss of inhibitory activity occurs in latent plasminogen activator inhibitor-1 (PAI-1 $)^{1}(9)$ and can also be induced to give the L-form of antithrombin (7) shown in Fig. $1 c$. There is also a further conformation (not shown) in which the reactive center of one serpin molecule inserts into a $\beta$-pleated sheet of the next molecule to give end-to-end polymerization (10). Such loopsheet polymerization can result from exposure to mild denaturants or to heat. Polymerization has also been observed to occur spontaneously with pathological variants of two serpins: $\alpha_{1^{-}}$ antitrypsin $(10,11)$ and $\mathrm{C}_{1}$-inhibitor (12).

Here we report the identification of a new variant of antithrombin (Rouen-VI 187 Asn $\rightarrow$ Asp) which as well as undergoing spontaneous polymerization also forms a stable inactive monomeric form with the properties of L-antithrombin. These changes take place slowly at $37^{\circ} \mathrm{C}$ but the demonstration that they are greatly accelerated at $41^{\circ} \mathrm{C}$ provides an explanation for the observed association of thrombotic episodes with incidental pyrexial infections. The occurrence of L-state formation in conjunction with the formation of short-chain polymers fits with recent structural studies of antithrombin $(7,13)$ to provide insights into the mechanism of loop-sheet polymerization.

\section{Methods}

Antithrombin assays and inhibitory activity. Plasma antithrombin antigen was measured by electroimmunoassay (14), and its thrombin inhibitory activity was determined (15) in the presence and absence of heparin using the chromogenic substrate Chromozym TH (Boehringer Mannheim UK [Diagnostics and Biochemicals] Ltd., East Sussex, United Kingdom). To determine the specific activity of isolated antithrombin, human $\alpha$-thrombin (a gift of Dr. Jean-Marie Freyssinet, Université Louis Pasteur Strasbourg, Institut d'Hématologie et d'Immunologie, Stras-

1. Abbreviations used in this paper: HA, high affinity; LA, low affinity; PAI-1, plasminogen activator inhibitor-1; TUG, transverse urea gradient. 
a

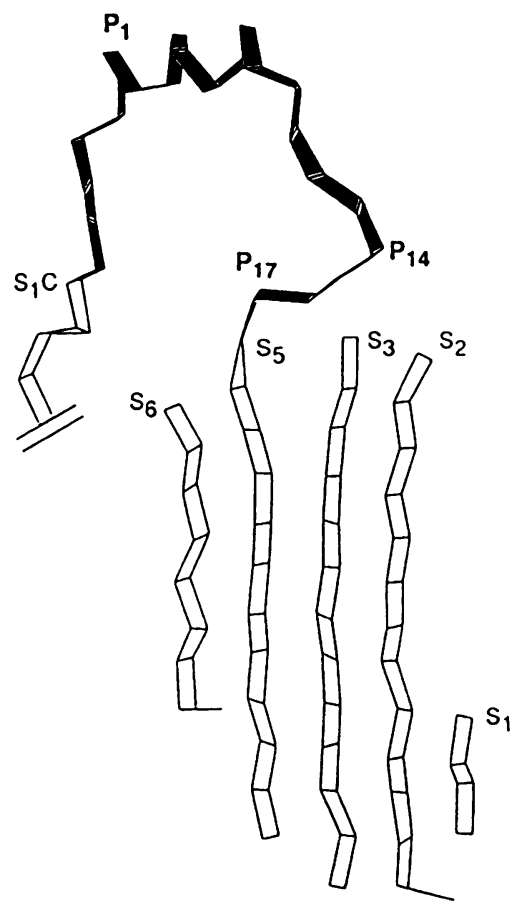

b

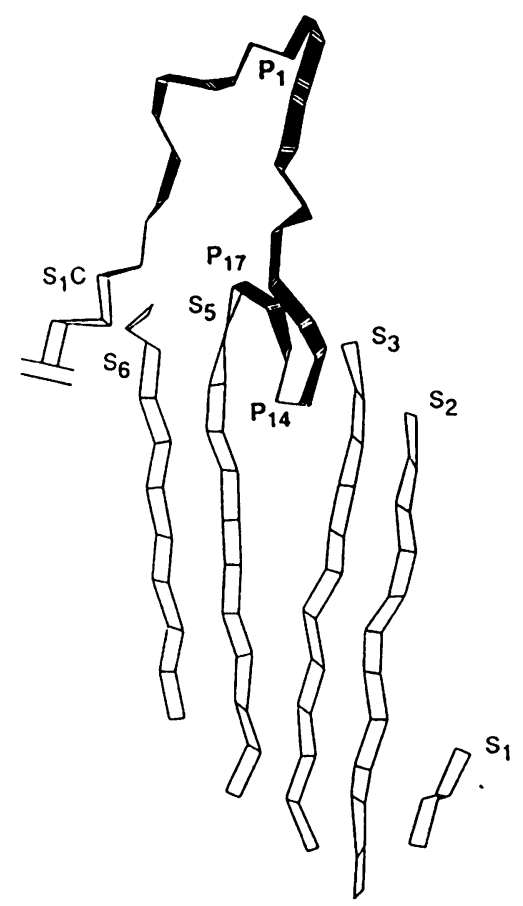

Figure 1. Conformational flexibility of the serpin reactive center loop. Schematic representations of three different conformations of the reactive center loop (black) and the central A- $\beta$-sheet (white) are depicted. In $a$ the conformation found in the noninhibitory serpin, ovalbumin (5), is shown and is characterized by a closed, five-stranded A-sheet from which the reactive center loop is totally excluded and adopts a three-turn helix. Active $\alpha_{1}$-antichymotrypsin has a similar conformation but with considerable distortions of the helix (9). In $b$ the A-sheet of active antithrombin $(6,7)$ is seen to be half open allowing partial insertion of the reactive center loop which does not contain helical structure. $c$ shows the L-form structure of antithrombin (7) and is essentially identical to that seen in latent PAI-1 (9) with the loop fully inserted into the A-sheet. To facilitate the total incorporation of the loop in this manner, strand 1 of the $\mathrm{C}$ - $\beta$-sheet $\left(\mathrm{s}_{1} \mathrm{C}\right)$ has been displaced and becomes part of the "latent loop" which comprises the $\mathrm{P}_{2}-\mathrm{P}_{13}$ ' residues. The diagrams were produced as described by Lesk and Hardman (34) using coordinates from the crystal structures of intact ovalbumin for $a(5)$ and intact antithrombin for $b$ and $c(7)$.

bourg, France) was first titrated using $p$-nitrophenyl $p^{\prime}$-guanidinobenzene to determine the concentration of active protease. Dilutions of antithrombin between 0 and 50 pmol (estimated from the extinction coefficient $\mathrm{E}_{280}^{1 \%}=6.5$ [16]) were then titrated against 20 pmol of thrombin in kinetics assay buffer $(50 \mathrm{mM}$ Tris $/ \mathrm{HCl}, 150 \mathrm{mM} \mathrm{NaCl}, 0.1 \%$ PEG-6000, pH 8.2) using the substrate S-2288 (Chromogenix, Mölndal, Sweden). Before adding substrate ( $800 \mu \mathrm{l}$ of $0.01 \%$ in kinetics assay buffer), thrombin and antithrombin were incubated together for $2 \mathrm{~h}$ at $23^{\circ} \mathrm{C}$ in a total volume of $200 \mu \mathrm{l}$.

The association rate constants of the antithrombin samples with thrombin, in both the presence and absence of heparin, were determined under pseudo first-order conditions using a modification of the procedure described by Rovelli et al. (17). When using heparin, 15 different heterogeneous and high affinity (HA) heparin concentrations, ranging from 1 to $3,000 \mathrm{nM}$, and 12 different low affinity (LA) heparin concentrations, from 50 to $10,000 \mathrm{nM}$, were added to cuvettes containing 10 $\mathrm{nM}$ antithrombin. The S-2288 substrate was then added (79-318 $\mu \mathrm{M}$ for heterogeneous and HA heparins and $79 \mu \mathrm{M}$ for LA heparin), and the cuvettes were incubated at $37^{\circ} \mathrm{C}$ for $10 \mathrm{~min}$. Human $\alpha$-thrombin was then added (100-500 pM for heterogeneous and HA heparins and $20 \mathrm{pM}$ for LA heparin), and the $p$-nitroaniline release from the substrate was continuously monitored at $405 \mathrm{~nm}$ over a $30-\mathrm{min}$ period on a diode array spectrophotometer (Hewlett-Packard Co., Palo Alto, CA). Substrate and thrombin concentrations in the assay were varied to allow a slow transition to the steady state and to permit accurate determination of the rate constants. The steady state velocities obtained at each heparin concentration were then calculated by weighted nonlinear regression from which the rate constants were calculated and plotted against the $\log$ of the heparin concentrations. The peaks of the resulting bell-shaped curves represented the maximum association rate constants for each heparin type. A similar method was used to calculate the association rate constant in the absence of heparin (progressive activity), except that a $1 \mu \mathrm{M}$ concentration of antithrombin was used with $20 \mathrm{pM}$ thrombin and $79 \mu \mathrm{M}$ of S-2288 and the reaction was monitored over $60 \mathrm{~min}$.

Amplification and direct sequencing of amplified DNA. High molecular weight DNA for use in the PCR was extracted from 10-20 ml of citrated whole blood. Synthetic oligonucleotide primers were designed to amplify each of the exons of the antithrombin gene including the intron-exon splice sites. Amplification primers were synthesized on a DNA synthesizer (Applied Biosystems, Inc., Foster City, CA) and were used without further purification. Amplification reactions were performed in $100 \mu \mathrm{l}$ reaction volumes containing $1 \mu \mathrm{g}$ of genomic DNA, $200 \mu \mathrm{mol}$ of each dNTP (dATP, dCTP, dGTP, and dTTP), 100 pmol of each amplification primer in the presence of $50 \mathrm{mM} \mathrm{KCl}, 10 \mathrm{mM}$ Tris $/ \mathrm{HCl}\left(\mathrm{pH} 8.3\right.$ ), and $1.5 \mathrm{mM} \mathrm{MgCl}_{2}$. Samples were heated to $100^{\circ} \mathrm{C}$ for 5 min to denature the DNA, spun briefly, and placed in a Thermocycler (Perkin-Elmer, Beaconsfield, United Kingdom) at the annealing temperature appropriate for the primer pair. $2 \mathrm{U}$ of Thermus aquaticus Amplitaq (Perkin-Elmer) was then added to each sample, the tubes were overlaid with $100 \mu \mathrm{l}$ of light mineral oil, and 40 rounds of amplification were performed. After amplification, $10 \mu \mathrm{l}$ of each product was run on a $1.5 \%$ agarose gel to check the efficiency and specificity of the reaction.

After amplification, the PCR product was purified by electrophoresis in $1 \%$ low-gelling-temperature agarose in $40 \mathrm{mM}$ Tris-acetate, $1 \mathrm{mM}$ EDTA, pH 8.0. The PCR product was then excised under low intensity 


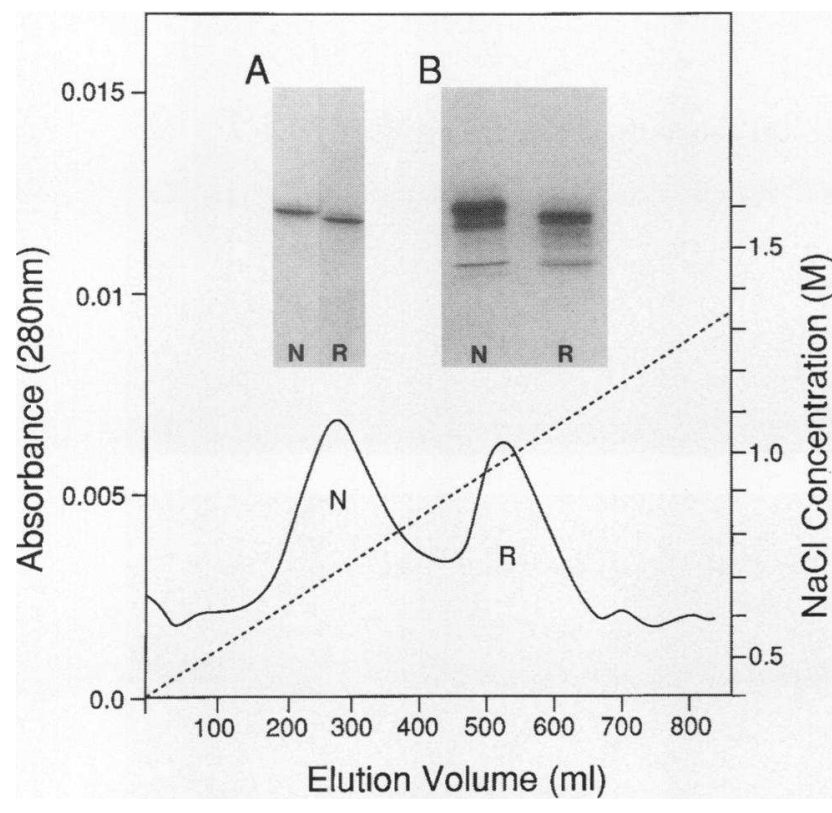

Figure 2. Antithrombin elution profile from heparin-Sepharose chromatography of plasma from a subject heterozygous for antithrombin RouenVI. Antithrombin isoforms were eluted from the column with a linear salt gradient from 0.4 to $1.5 \mathrm{M}$ (dotted line). $N$, native antithrombin; $R$, antithrombin Rouen-VI. Inset $A$ shows nondenaturing polyacrylamide gel electrophoresis, and inset $B$ shows isoelectric focusing of both antithrombin isoforms, with the more anodal migration of antithrombin Rouen-VI on both systems being consistent with this variant having an additional negative charge relative to native antithrombin.

ultraviolet light, and the DNA was extracted from the agarose matrix by subjecting the gel slice to two rounds of freeze-thawing. The gel solution was then centrifuged in a microfuge, and the supernatant was extracted once with phenol/chloroform (1:1) and then by a single chloroform extraction, and the DNA was recovered by ethanol precipitation. The DNA pellet was washed in $70 \%$ ethanol, dried, and resuspended in $20 \mu \mathrm{l}$ of sterile water. Nested sequencing primers, i.e., internal to the amplification primers, were used to sequence the coding and noncoding DNA strands and were purified before use on $20 \%$ denaturing polyacrylamide gels. Sequencing using a modified Sanger dideoxy protocol was otherwise as published previously (18). The sequences for the amplification and sequencing oligonucleotides are available on request.

Preparation of heparin Sepharose. Heterogeneous porcine heparin (Grampian Enzymes, Arthrath, United Kingdom) was coupled to Sepharose CL-4B (Pharmacia AB, Uppsala, Sweden) by cyanogen bromide activation (19) using $6 \mathrm{mg}$ heparin per milliliter of resin. HA and LA fractions of size fractionated heparin (mean molecular mass $=15 \mathrm{kD}$ ) were prepared (20) using an affinity column (21) of antithrombin coupled to Affigel-15 (Biorad Laboratories, Hertfordshire, United Kingdom). Each fraction was titrated in an antithrombin/thrombin (molar ratio $2: 1$ ) inhibitory assay, and fractions with little or no potentiation of thrombin inhibition by antithrombin were pooled as LA heparin. Fractions with the highest affinity for the column showed maximum inhibitory activity in the assay and were pooled as HA heparin. Fractions displaying an intermediate activity between these two extremes were discarded as being heterogeneous for both forms. HA and LA heparin columns were made in the same way as for heterogeneous heparin Sepharose.

Isolation of antithrombin. Antithrombin was isolated from plasma using the heterogeneous heparin Sepharose according to the method of McKay (22). Residual heparin was removed on an anion exchange column ( Poros Q; PerSeptive Biosystems, Cambridge, MA) equilibrated in $20 \mathrm{mM}$ Tris $/ \mathrm{HCl}, \mathrm{pH} 7.4$, using a linear gradient from 0 to $1 \mathrm{M}$
Table I. Antithrombin Rouen-VI Association Rate Constants with Thrombin

\begin{tabular}{lcc}
\hline \multirow{2}{*}{ Heparin type } & \multicolumn{2}{c}{$K_{\text {as }}\left(\mathrm{M}^{-1} \mathrm{~s}^{-1}\right)$} \\
\cline { 2 - 3 } & $\begin{array}{c}\text { Native antithrombin* } \\
\text { (mean } \pm \mathrm{SD})\end{array}$ & $\begin{array}{c}\text { Antithrombin Rouen-VI } \\
(\text { mean } \pm \text { SD })\end{array}$ \\
\hline None & $(1.79 \pm 0.49) \times 10^{4}$ & $(2.21 \pm 0.09) \times 10^{4}$ \\
Heterogeneous & $(7.84 \pm 0.89) \times 10^{7}$ & $(5.53 \pm 0.18) \times 10^{7}$ \\
15-kD LA & $(5.46 \pm 0.14) \times 10^{6}$ & $(5.14 \pm 0.01) \times 10^{6}$ \\
15-kD HA & $(10.13 \pm 0.90) \times 10^{7}$ & $(7.43 \pm 0.15) \times 10^{7}$
\end{tabular}

* Values for native antithrombin represent the mean $\pm \mathrm{SD}$ of eight independent measurements. ${ }^{\ddagger}$ Values for antithrombin Rouen-VI represent mean $\pm \mathrm{SD}$ of two independent measurements.

$\mathrm{NaCl}$. The antithrombin $(1 \mathrm{mg} / \mathrm{ml}$ in $20 \mathrm{mM}$ Tris/ $\mathrm{HCl}, \mathrm{pH} 8.0)$ was snap-frozen in liquid nitrogen in $100-\mu \mathrm{g}$ aliquots and stored at $-80^{\circ} \mathrm{C}$ until use.

Preparation of latent and polymerized antithrombin. The latent form of antithrombin was induced by heat incubation rather than by exposure to denaturants, as thermal incubation gives better yields and the presence of citrate inhibits polymer formation. Native antithrombin $(10 \mathrm{mg})$ at a concentration of $1 \mathrm{mg} / \mathrm{ml}$ in $20 \mathrm{mM}$ Tris/ $\mathrm{HCl}, 0.25 \mathrm{M}$ trisodium citrate, $\mathrm{pH} 7.4$, was incubated for $15 \mathrm{~h}$ at $60^{\circ} \mathrm{C}$. Under these conditions, $\sim 50 \%$ of the antithrombin is converted to the latent form, and this was isolated by heparin Sepharose using a linear gradient from 0 to $1 \mathrm{M}$ $\mathrm{NaCl}$ in $20 \mathrm{mM} \mathrm{Tris} / \mathrm{HCl}, \mathrm{pH}$ 7.4. Residual heparin and traces of polymers were removed from this early eluting material by anion exchange chromatography. On nondenaturing polyacrylamide gel electrophoresis, $>90 \%$ of the purified latent antithrombin migrated as a single band slightly more anodal than native antithrombin. The latent form was resistant to proteolytic cleavage of its reactive center loop, had negligible inhibitory activity, and had increased stability with no unfolding transition in urea gels.

Polymerized antithrombin was prepared by partial denaturation in dilute guanidinium $/ \mathrm{HCl} .5 \mathrm{mg}(500 \mu \mathrm{l}$ of $10 \mathrm{mg} / \mathrm{ml})$ of native antithrombin was added to $6.65 \mathrm{ml} 50 \mathrm{mM}$ Tris/ $\mathrm{HCl}, 50 \mathrm{mM} \mathrm{NaCl}, 0.9 \mathrm{M}$ $\mathrm{GdHCl}, \mathrm{pH} 7.6$, to give a final protein concentration of $0.7 \mathrm{mg} / \mathrm{ml}$ and incubated at $4^{\circ} \mathrm{C}$ for $16 \mathrm{~h}$. The antithrombin solution was then diluted fourfold with dialysis buffer ( $50 \mathrm{mM}$ sodium phosphate, $10 \mathrm{mM} \mathrm{NaCl}$, $\mathrm{pH}$ 7.2) and extensively dialyzed to remove the guanidine, then concentrated in an Amicon cell, and applied to heterogeneous heparin-Sepharose and anion exchange chromatography as for latent antithrombin. Polymers had decreased heparin affinity but bound more tightly to the anion exchange resin relative to monomeric native antithrombin, eluting from the Poros Q column as a broad peak late in the gradient.

Polyacrylamide gel electrophoresis. Sodium dodecyl sulfate (SDS )polyacrylamide gel electrophoresis was performed using 10-20\% gradient slab gels according to the method of Laemmli (23) but substituting 2-amino-2-methyl-1,3-propanediol for Tris. Nondenaturing polyacrylamide gel electrophoresis was performed, at $\mathrm{pH} 8.9$, in $7.5-15 \%$ gradient slab gels using $52.9 \mathrm{mM}$ Tris $/ \mathrm{HCl}, 68.4 \mathrm{mM}$ glycine, $\mathrm{pH} 8.2$, for

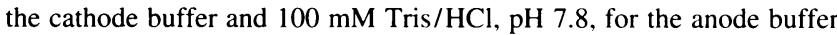
(24). For both systems, 3-5 $\mu \mathrm{g}$ of antithrombin, generally not reduced, was loaded per lane. Transverse urea gradient (TUG) polyacrylamide mini gels were prepared with the same buffer system as that used for nondenaturing polyacrylamide gel electrophoresis using a linear gradient from 0 to $8 \mathrm{M}$ urea in $7.5 \%$ ( wt $/ \mathrm{vol}$ ) acrylamide (24-26). Antithrombin $(50 \mu \mathrm{g})$ was applied evenly across the top of the gel, and electrophoresis was performed at $15 \mathrm{~mA}$ constant current for $90 \mathrm{~min}$. Isoelectric focusing was performed in 5\% polyacrylamide gels containing $4 \%$ Ampholine, $\mathrm{pH} 4-6$, essentially as described by the manufacturers (Pharmacia AB ). Approximately $25 \mu \mathrm{g}$ of protein sample was loaded on each lane at the cathode end of the gel after first prefocusing the gel. 

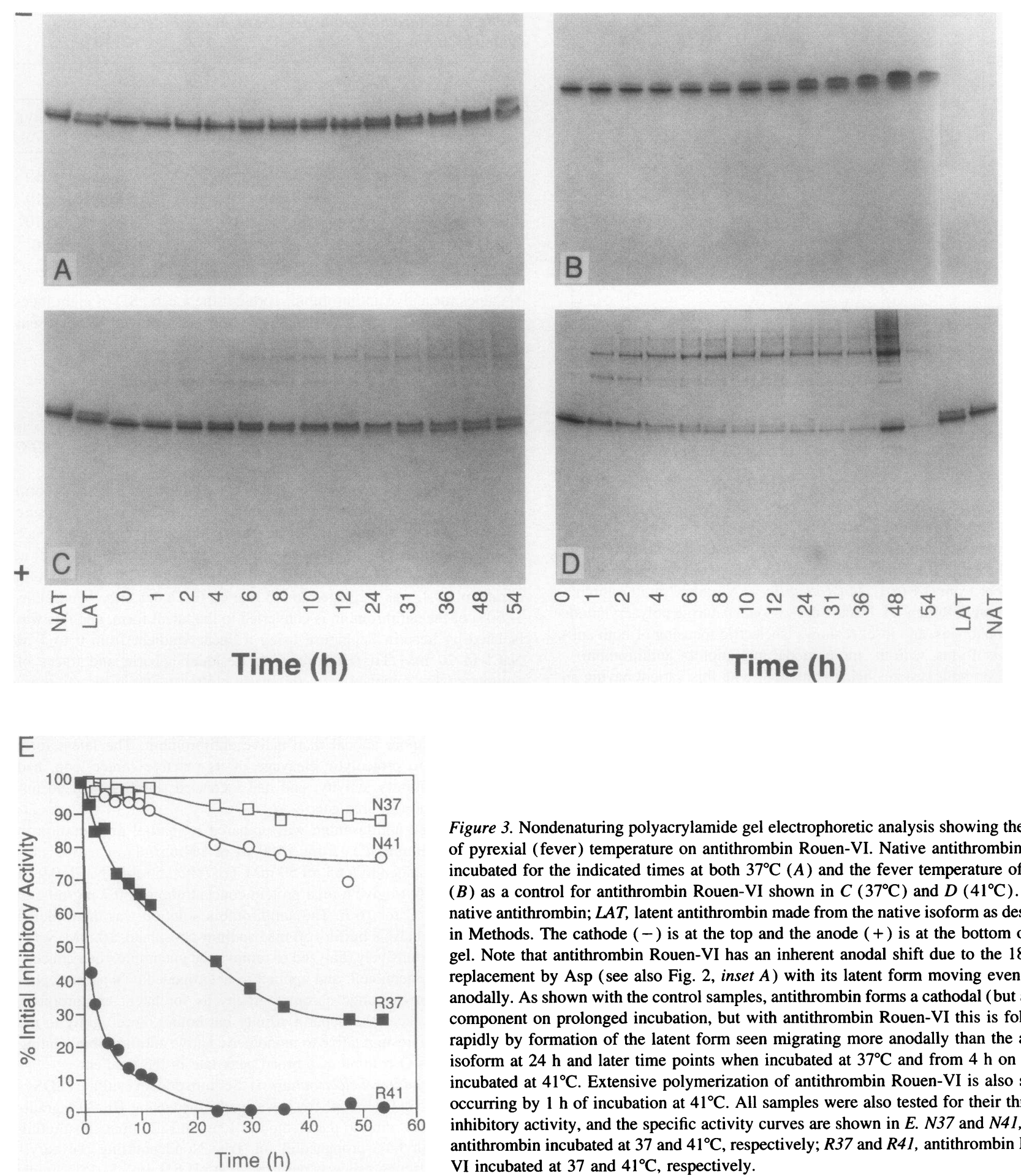

Figure 3. Nondenaturing polyacrylamide gel electrophoretic analysis showing the effect of pyrexial (fever) temperature on antithrombin Rouen-VI. Native antithrombin was incubated for the indicated times at both $37^{\circ} \mathrm{C}(A)$ and the fever temperature of $41^{\circ} \mathrm{C}$ $(B)$ as a control for antithrombin Rouen-VI shown in $C\left(37^{\circ} \mathrm{C}\right)$ and $D\left(41^{\circ} \mathrm{C}\right)$. NAT, native antithrombin; $L A T$, latent antithrombin made from the native isoform as described in Methods. The cathode $(-)$ is at the top and the anode $(+)$ is at the bottom of each gel. Note that antithrombin Rouen-VI has an inherent anodal shift due to the 187-Asn replacement by Asp (see also Fig. 2, inset $A$ ) with its latent form moving even more anodally. As shown with the control samples, antithrombin forms a cathodal (but active) component on prolonged incubation, but with antithrombin Rouen-VI this is followed rapidly by formation of the latent form seen migrating more anodally than the active isoform at $24 \mathrm{~h}$ and later time points when incubated at $37^{\circ} \mathrm{C}$ and from $4 \mathrm{~h}$ on when incubated at $41^{\circ} \mathrm{C}$. Extensive polymerization of antithrombin Rouen-VI is also seen occurring by $1 \mathrm{~h}$ of incubation at $41^{\circ} \mathrm{C}$. All samples were also tested for their thrombin inhibitory activity, and the specific activity curves are shown in $E . N 37$ and $N 41$, native antithrombin incubated at 37 and $41^{\circ} \mathrm{C}$, respectively; $R 37$ and $R 41$, antithrombin RouenVI incubated at 37 and $41^{\circ} \mathrm{C}$, respectively.

Insertion of a synthetic peptide into antithrombin. A synthetic 11mer peptide (Ac-SEAAASTAVVI) representing the sequence between $P_{14}$ and $P_{4}$ of the antithrombin reactive center loop was used in the peptide insertion experiments. $50 \mu \mathrm{g}$ of antithrombin $(1 \mathrm{mg} / \mathrm{ml}$ in 20 $\mathrm{mM}$ Tris $/ \mathrm{HCl}, \mathrm{pH} 8.0$ ) was incubated with 100 -fold molar excess of the peptide at $37^{\circ} \mathrm{C}$ for $24 \mathrm{~h}$. At different time points during the incubation, $5-\mu \mathrm{l}$ aliquots ( $5 \mu \mathrm{g}$ ) were removed, added to $20 \mu \mathrm{l}$ of nondenaturing polyacrylamide gel loading buffer $\left(0.24 \mathrm{M}\right.$ Tris $/ \mathrm{H}_{3} \mathrm{PO}_{4}, 10 \%$ glycerol, $0.2 \%$ Tween $20,0.04 \%$ bromophenol blue, $\mathrm{pH} 6.9$ ), and snap-frozen in liquid nitrogen and stored at $-80^{\circ} \mathrm{C}$ until use. At the conclusion of the incubation period, the aliquots were thawed and immediately electrophoresed on a nondenaturing $7.5-15 \%$ polyacrylamide gradient gel.

Limited proteolysis of antithrombin. $100 \mu \mathrm{g}$ of antithrombin $(1 \mathrm{mg} /$ $\mathrm{ml}$ in $20 \mathrm{mM}$ Tris $/ \mathrm{HCl}, \mathrm{pH} 8.0$ ) was preincubated at $37^{\circ} \mathrm{C}$ for $10 \mathrm{~min}$, and then $0.4 \mu \mathrm{g}$ of human neutrophil elastase (1:250 wt/wt) was added; the solution was mixed and incubated further at $37^{\circ} \mathrm{C}$. At various time points, a $5-\mu \mathrm{l}$ aliquot ( $5 \mu \mathrm{g}$ ) was removed and added to $20 \mu \mathrm{l}$ of SDSpolyacrylamide gel loading buffer $(62.5 \mathrm{mM}$ Tris/ $\mathrm{HCl}, 3 \%$ SDS, $10 \%$ glycerol, $\mathrm{pH} 6.8$ ), snap-frozen in liquid nitrogen, and stored at $-80^{\circ} \mathrm{C}$ 
until use. After the last time point $(2 \mathrm{~h})$ the frozen aliquots were heated for $5 \mathrm{~min}$ at $90^{\circ} \mathrm{C}$ and electrophoresed on a $10-20 \%$ SDS-polyacrylamide gradient gel.

Effect of temperature on antithrombin. 100- $\mu \mathrm{g}$ aliquots of native and variant antithrombin preparations $(1 \mathrm{mg} / \mathrm{ml}$ in $20 \mathrm{mM}$ Tris $/ \mathrm{HCl}$, $\mathrm{pH} \mathrm{8.0)}$ were incubated at both 37 and $41^{\circ} \mathrm{C}$. At the various time points indicated in the figures, $5-\mu$ l aliquots were removed and added to 20 $\mu \mathrm{l}$ of nondenaturing polyacrylamide gel loading buffer, snap-frozen in liquid nitrogen, and stored at $-80^{\circ} \mathrm{C}$ until use. After the last time point at $54 \mathrm{~h}$ the samples were thawed and immediately electrophoresed on a nondenaturing $7.5-15 \%$ polyacrylamide gradient gel. The thrombin inhibitory activity of the antithrombin samples was also monitored over the 54-h incubation period. For this, 5- $\mu \mathrm{l}$ aliquots were removed from tubes incubated in parallel at the two temperatures and diluted to a concentration of $1 \mu \mathrm{M}$ in kinetics assay buffer, snap-frozen in liquid nitrogen, and stored at $-80^{\circ} \mathrm{C}$ until use. At the end of the incubation period, the samples were thawed, and the specific activity of each was determined as already described. A similar analysis was carried out to determine the effect of pyrexial (fever) temperature on whole plasma. For this, 1-ml plasma samples from both a subject with antithrombin Rouen-VI and a normal subject were incubated at $41^{\circ} \mathrm{C}$. At different times up to $48 \mathrm{~h}, 50-\mu \mathrm{l}$ aliquots were removed, snap-frozen in liquid nitrogen, and stored at $-80^{\circ} \mathrm{C}$ until use. At the conclusion of the incubation period, the aliquots were thawed and tested for antithrombin activity using an assay kit (Immunochrom AT3; Immuno Ltd., Kent, United Kingdom) and research coagulometer (ACL 300; Instrumentation Laboratory [UK] Ltd., Cheshire, United Kingdom).

\section{Results}

Clinical history. The propositus is a 40 -yr-old woman who at the age of 29 , during her first pregnancy, developed a deep venous thrombosis. She subsequently had two further thrombotic episodes both occurring during pregnancy and both resulting in miscarriages. In each case, the thrombotic event was accompanied by an unrelated pyrexial infection. The father of the propositus had a history of thromboembolic disease, having experienced his first venous thrombosis at the age of 20 in association with a severe pneumonia.

Characterization and isolation of antithrombin. In fresh plasma obtained from the propositus, the total antithrombin antigenic level was within the normal range of six control subjects and the progressive $(85 \%)$ and heparin-induced $(84 \%)$ activities were each compatible with normal function. Amplification of exon $3 \mathrm{~b}$ from genomic DNA, and direct sequencing, showed in each of three separate samples that two nucleotides occurred at position 6460 within codon 187 , indicating a heterozygous state for both the normal allele AAC, encoding asparagine, and a variant allele GAC, coding for aspartate. Complete sequencing of other exons showed no other abnormality. The $A \rightarrow G$ substitution in the first nucleotide of codon 187 creates a new recognition site for the restriction enzyme Taq1, permitting rapid confirmation of the mutation. This variant, 187 Asn $\rightarrow$ Asp, has been designated antithrombin Rouen-VI.

The discrepancy between the apparently normal functional measurements and the history of thrombotic disease was clarified by subsequent assays of plasma antithrombin. The antithrombin activities measured on fresh plasma at the laboratory of origin were within the normal range, but after transport and a week's storage at $4^{\circ} \mathrm{C}$ the activities regressed to as low as $50-60 \%$ of normal. Similar findings were obtained with isolated antithrombin Rouen-VI which could be purified as a result of its having an increased heparin affinity (Fig. 2). The specific activities of two independently isolated preparations against $\alpha$ -
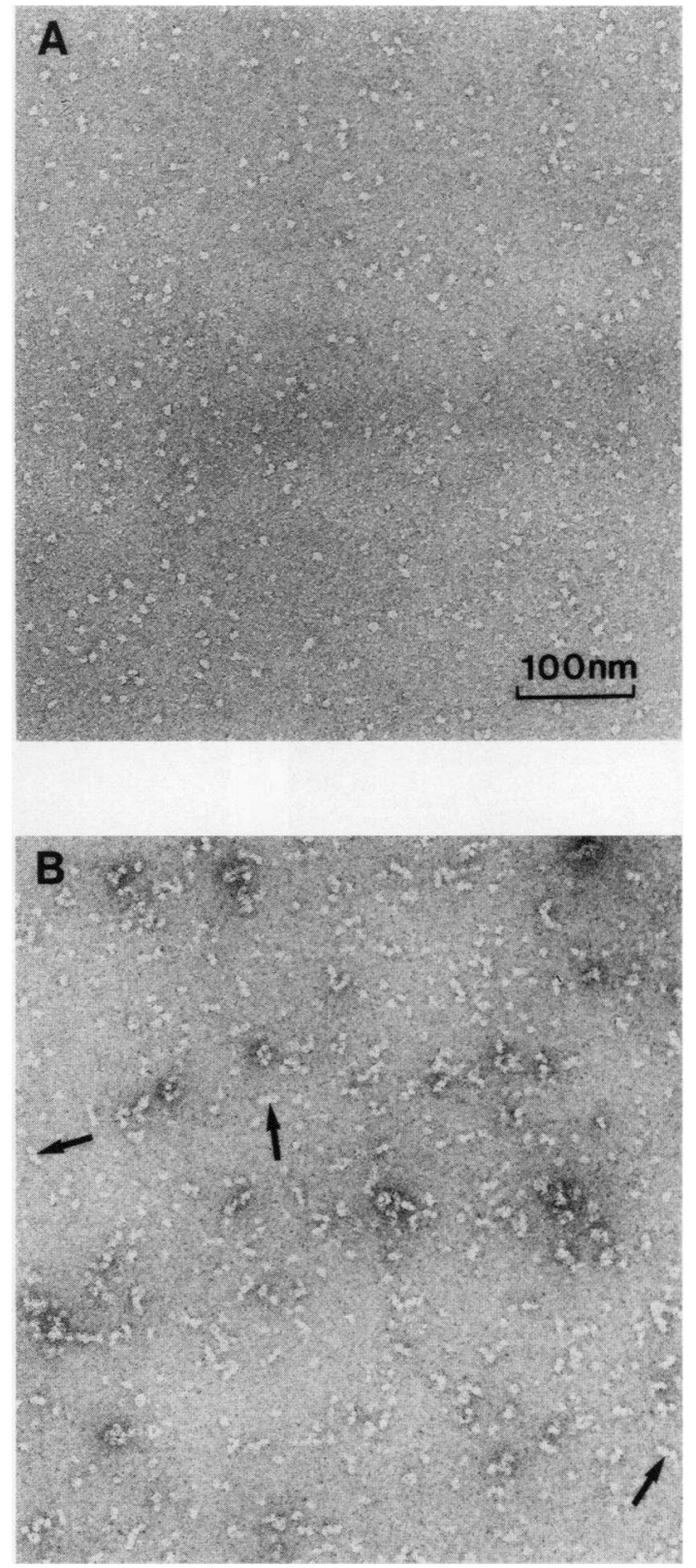

Figure 4. Electron microscopy of antithrombin Rouen-VI after incubation at fever temperature $\left(41^{\circ} \mathrm{C}\right)$. Native antithrombin $(A)$ and antithrombin Rouen-VI $(B)$ were incubated at $41^{\circ} \mathrm{C}$ for $20 \mathrm{~h}$, negatively stained with uranyl acetate, and viewed at a magnification of 123,000 . Antithrombin Rouen-VI forms predominantly short chain polymers, mostly trimers (arrows), consistent with Fig. $3 D$, whereas native antithrombin remains almost totally monomeric when treated in this way. The size bar in $A$ also refers to $B$.

thrombin were 67 and $87 \%$ compared with 77 and $74 \%$ for the related control preparations. The association rates of antithrombin Rouen-VI with thrombin in the absence and presence of various heparin fractions were determined by pseudo first-order kinetics (Table I). The results indicate that the inhibitory activity of antithrombin Rouen-VI toward its cognate protease thrombin is little perturbed by the mutation. However, it became apparent that the specific activity of isolated antithrombin Rouen-VI decreased on storage; after storage for 4 wk at $4^{\circ} \mathrm{C}$ 

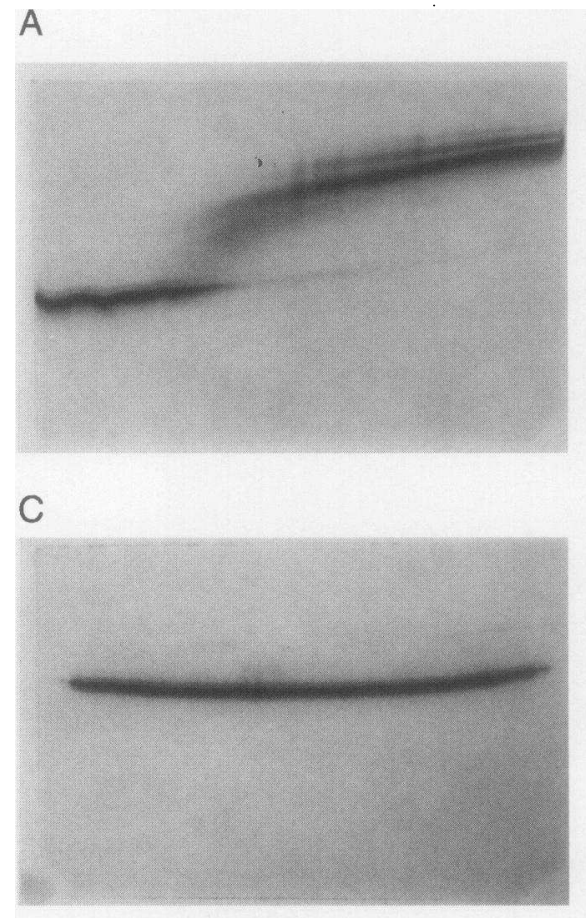

E

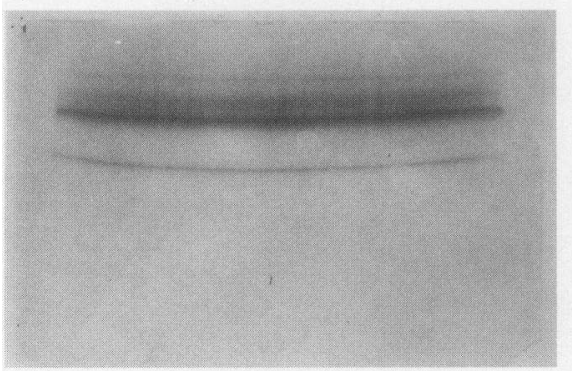

B

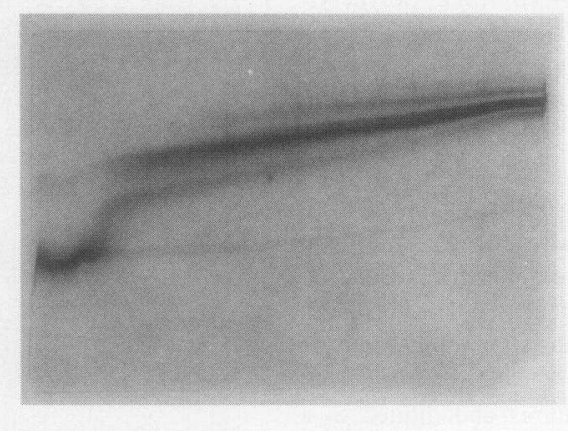

D

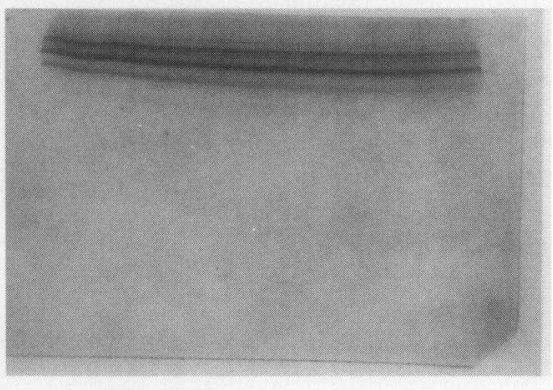

F

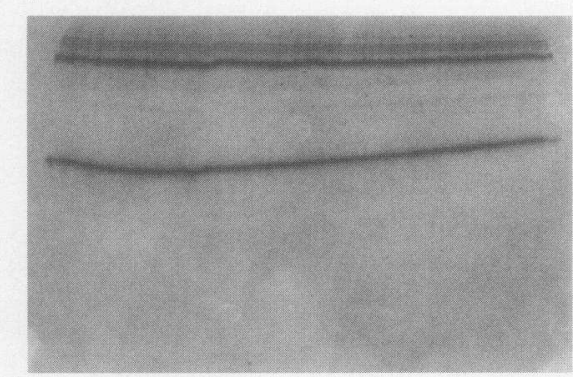

Figure 5. Conformational stability analysis of different antithrombin preparations by TUG polyacrylamide gel electrophoresis. Each panel represents one sample run on a single gel with the direction of migration from the top (cathode) to bottom (anode) and the urea gradient $(0-8 \mathrm{M}$ in all panels except $E$, which is $1-8 \mathrm{M}$ ) from left to right. $A$, native antithrombin; $B$, freshly isolated antithrombin Rouen-VI; $C$, latent antithrombin prepared by heat pasturization of native material as described in Methods; $D$, polymerized native antithrombin prepared by partial $\mathrm{GdHCl}$ denaturation as described in Methods; $E$, antithrombin Rouen-VI after 4 wk of storage at $4^{\circ} \mathrm{C}$ (for clarity: urea gradient 1-8 M); $F$, antithrombin Rouen-VI after $20 \mathrm{~h}$ of incubation at $41^{\circ} \mathrm{C}$. antithrombin Rouen-VI retained only $39 \%$ of its initial activity compared with no loss of activity for native control antithrombin. Further studies were then undertaken to determine the basis for this loss of inhibitory activity upon standing.

Loss of activity of antithrombin Rouen-VI. Temperature effect. To investigate further the accelerated loss of activity of antithrombin Rouen-VI, the isolated variant and normal antithrombin were incubated at 37 and at $41^{\circ} \mathrm{C}$ (which represents a pyrexial/fever temperature). Neither incubation at 37 nor $41^{\circ} \mathrm{C}$ had a significant effect on the electrophoretic profile of control antithrombin (Fig. 3, $A$ and $B$ ) or its inhibitory activity. Prolonged incubation of control antithrombin at $37^{\circ} \mathrm{C}$ for $54 \mathrm{~h}$ resulted in only a $13.5 \%$ reduction of its initial inhibitory activity, and incubation at $41^{\circ} \mathrm{C}$ for $54 \mathrm{~h}$ gave a $25 \%$ reduction (Fig. $3 E$ ). However, antithrombin Rouen-VI lost $70 \%$ of its activity after $40 \mathrm{~h}$ at $37^{\circ} \mathrm{C}$ and had a complete loss of activity after only $20 \mathrm{~h}$ at $41^{\circ} \mathrm{C}$ (Fig. $3 \mathrm{E}$ ). Similarly, there was a significant loss of activity from unfractionated plasma that had been incubated at $41^{\circ} \mathrm{C}$. Whereas plasma from a normal control gave a $10 \%$ reduction in thrombin inhibitory activity after incubation at $41^{\circ} \mathrm{C}$ for $48 \mathrm{~h}$, the plasma from a heterozygote containing $\sim 28 \%$ active antithrombin Rouen-VI gave a $33 \%$ overall reduction, equivalent to an $80 \%$ loss of activity of the variant, most loss occurring within $24 \mathrm{~h}$. At $39^{\circ} \mathrm{C}$, there was no loss of activity in the normal plasma even after $48 \mathrm{~h}$, but at $24 \mathrm{~h}$ the activity of the variant antithrombin in the patient's plasma had decreased by $27 \%$.

The shift from 37 to $41^{\circ} \mathrm{C}$ also affected the conformation of antithrombin Rouen-VI. Incubation of the variant at $37^{\circ} \mathrm{C}$ (Fig. $3 C$ ) gave limited polymerization, with the major loss of inhibitory activity at later time points being due to conversion to a new monomeric electrophoretic form, with the more anodal mobility of latent antithrombin Rouen-VI. At $41^{\circ} \mathrm{C}$ the loss of activity is predominantly due to polymerization but with conversion of the remaining monomer to the mobility of latent antithrombin Rouen-VI (Fig. $3 \mathrm{D}$ ). The 48-h sample in Fig. $3 \mathrm{D}$ (at $41^{\circ} \mathrm{C}$ ) clearly demonstrates the absence of cleaved antithrombin which would migrate in the same position as the starting material and indicates the predominance of short chain polymers and in particular the homotrimer. The absence of cleaved material in this sample was independently confirmed: SDS-polyacrylamide gel electrophoresis indicated that both the denatured polymeric and latent antithrombin Rouen-VI migrated together as a single band in the native intact position (data not shown; see Fig. 7 for characteristic migration position of cleaved antithrombin). This band, representing the total variant material incubated at $41^{\circ} \mathrm{C}$ for $48 \mathrm{~h}$, and the more anodally migrating latent antithrombin Rouen-VI band from the nondena- 

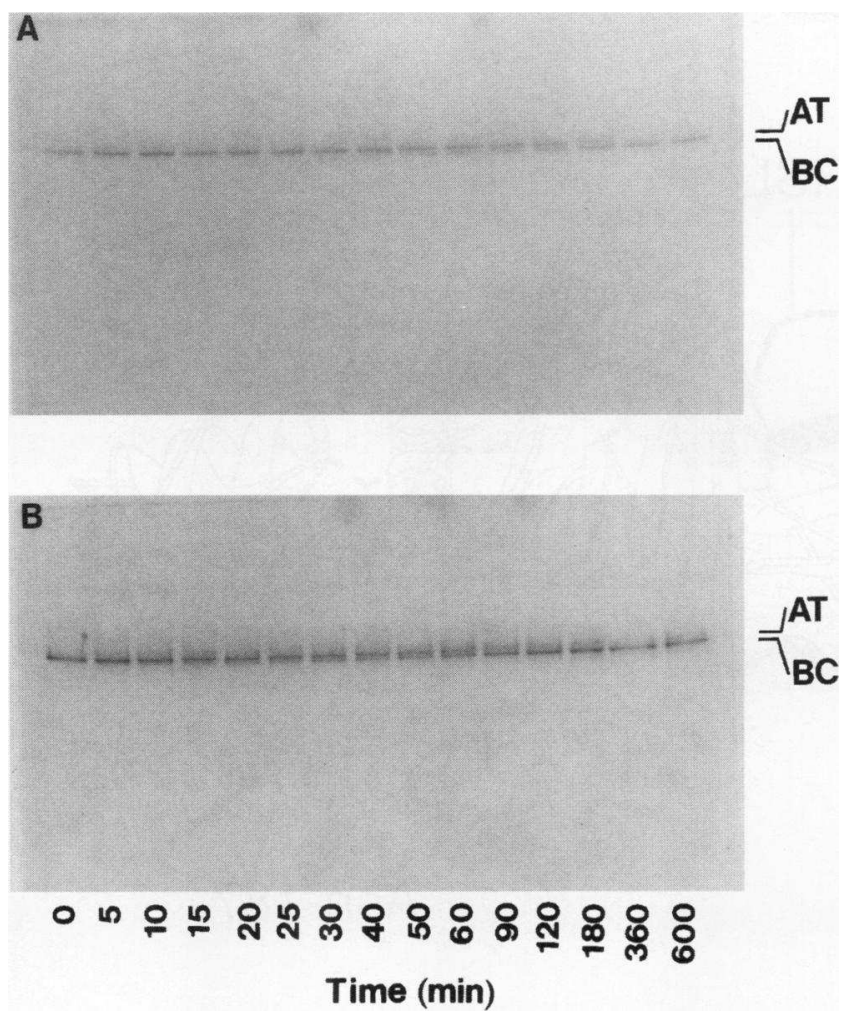

Figure 6. Nondenaturing polyacrylamide gel electrophoresis indicating the rate of antithrombin-synthetic peptide binary complex formation. A synthetic 11-mer reactive center loop peptide $\left(\mathrm{P}_{14}-\mathrm{P}_{4}\right)$ was incubated with native antithrombin $(A)$ and antithrombin Rouen-VI $(B)$ for the times indicated. $A T$, migration position of antithrombin free of peptide; $B C$, migration position of the binary complex formed when the synthetic peptide enters the $\mathrm{A}-\beta$-sheet of antithrombin.

turing polyacrylamide gel (Fig. $3 \mathrm{D}$ ) were transferred to polyvinyldifluoride membrane (Applied Biosystems, Inc.) and subjected to amino acid sequence analysis. In each case only a single sequence representing the amino terminus of antithrombin was found, again indicating that no cleavage had occurred. The short chain nature of the polymers was confirmed by electron microscopy (Fig. 4) of antithrombin Rouen-VI that had been incubated at $41^{\circ} \mathrm{C}$ at $1 \mathrm{mg} / \mathrm{ml}$ for $20 \mathrm{~h}$. Whereas the native antithrombin treated in parallel was almost exclusively monomeric (Fig. $4 \mathrm{~A}$ ) and still retained $85 \%$ of its original inhibitory activity, antithrombin Rouen-VI was mostly converted to short chain polymers, predominantly trimeric and tetrameric in size (Fig. $4 \mathrm{~B}$ ) and had completely lost inhibitory activity.

Further evidence of the occurrence of a slow spontaneous conformational change in the variant antithrombin is shown in the TUG polyacrylamide gel electrophoresis results in Fig. 5. Freshly isolated antithrombin Rouen-VI (Fig. 5 B) shows an unfolding transition like that of normal control antithrombin (Fig. $5 \mathrm{~A}$ ), except that the major conformational transition occurs at a significantly lower concentration of urea in keeping with the decreased conformational stability of the variant. Fig. 5, $C$ and $D$, show preparations of latent (Fig. $5 C$ ) and polymerized (Fig. $5 D$ ) control antithrombin. Fig. $5 E$ is isolated antithrombin Rouen-VI (run in a 1-8 M urea gradient) after $4 \mathrm{wk}$ of storage at $4^{\circ} \mathrm{C}$ showing the presence of latent and short chain
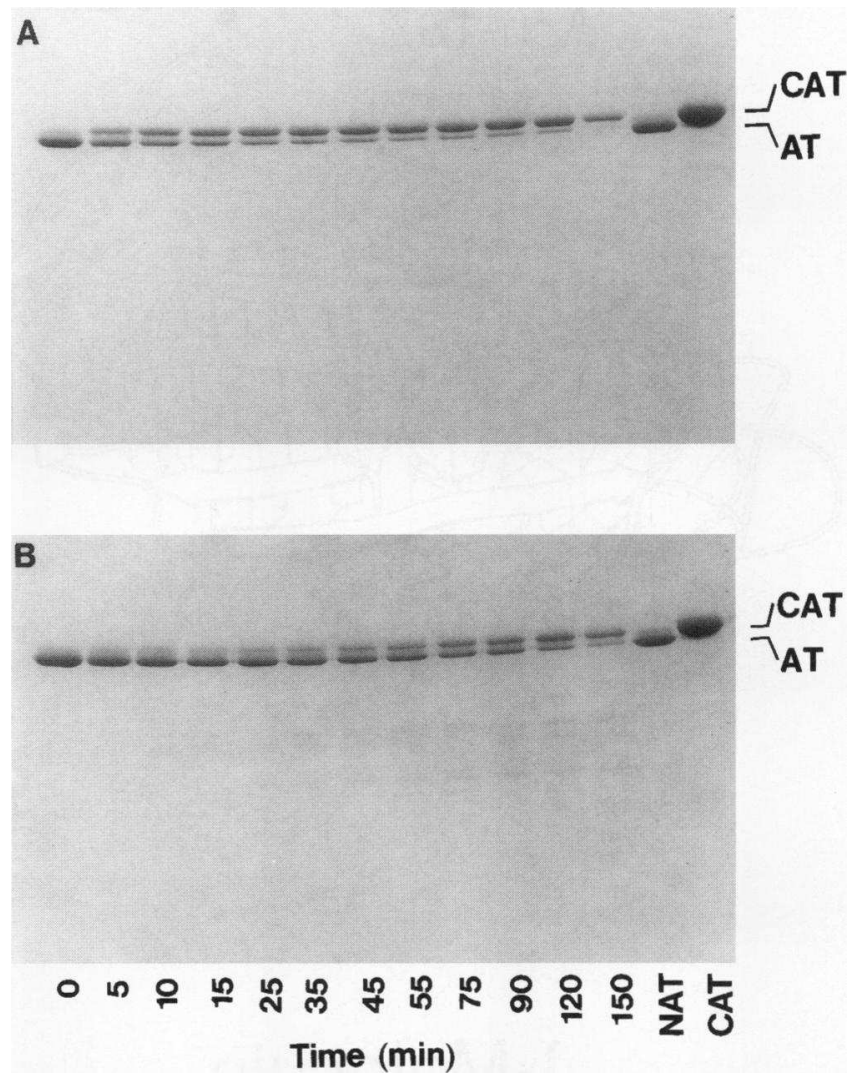

Figure 7. SDS-polyacrylamide gel electrophoresis indicating the rate of cleavage of the reactive loop of antithrombin by human neutrophil elastase. Native antithrombin $(A)$ and antithrombin Rouen-VI $(B)$, both at $1 \mathrm{mg} / \mathrm{ml}$ in $20 \mathrm{mM}$ Tris $/ \mathrm{HCl}, \mathrm{pH} 8.0$, were incubated with human neutrophil elastase $(1: 250 \mathrm{wt} / \mathrm{wt})$ for the times indicated. CAT, antithrombin cleaved at the $\mathrm{P}_{4}-\mathrm{P}_{3}$ (Ile-Ala) peptide bond in the reactive loop as determined by amino-terminal sequence analysis; $A T$, migration positions of intact native antithrombin $(A)$ and intact antithrombin Rouen-VI $(B) ; N A T$, intact, native antithrombin.

polymerized fractions; Fig. $5 F$ is of antithrombin Rouen-VI after $20 \mathrm{~h}$ of incubation at $41^{\circ} \mathrm{C}$ showing complete conversion to latent and polymerized forms.

Evidence of A-sheet conformational change: binary complex formation and limited proteolysis. The properties of the A$\beta$-sheet in the variant were investigated by incubating it at $37^{\circ} \mathrm{C}$ with the synthetic 11 -mer peptide Ac-SEAAASTAVVI, representing the sequence from $\mathrm{P}_{14}$ to $\mathrm{P}_{4}$ of the antithrombin reactive center loop. Aliquots from different incubation times were run on nondenaturing polyacrylamide gels where the binary complex migrates more anodally than the free inhibitor due to the acquisition of two additional negative charges contributed by the incorporated acetylated peptide. Fig. $6 \mathrm{~A}$ shows that with native control antithrombin the time at which half of the initial inhibitor had converted to binary complex $\left(t_{1 / 2}\right)$ was $110 \mathrm{~min}$. However, the rate of 11 -mer peptide insertion into antithrombin Rouen-VI (Fig. $6 \mathrm{~B}$ ) was considerably faster $\left(t_{1 / 2}=50 \mathrm{~min}\right)$ indicating that it is a better acceptor of the reactive site loop sequence and consistent with its propensity to form latent antithrombin. This was tested further by comparing the rates of cleavage by human neutrophil elastase of the $\mathrm{P}_{4}-\mathrm{P}_{3}$ (Ile-Ala) peptide bond $(25,27)$ in the reactive site loops of antithrombin Rouen-VI and native antithrombin. Cleavage 


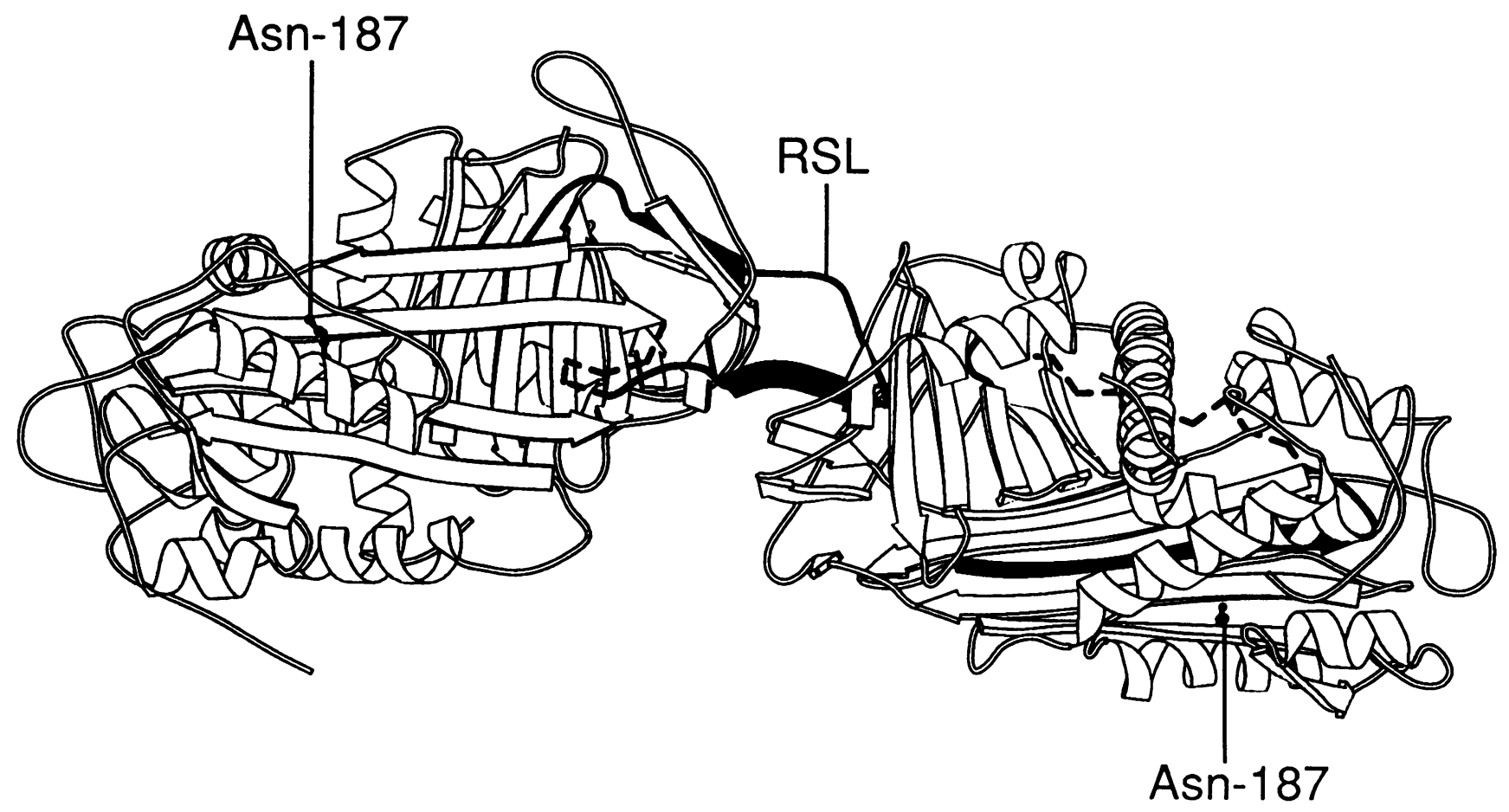

\section{I-Molecule}

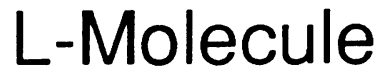

Figure 8. Schematic representation of the dimeric antithrombin present in the crystal structure. Dimers are formed by an unexpected mechanism involving the reactive site loop ( $R S L)$ of the I-molecule (inhibitory conformation) and the C- $\beta$-sheet of the L-molecule (locked or latent conformation). The full incorporation of the reactive site loop into the A- $\beta$-sheet in the L-molecule is accompanied by the necessary displacement of strand 1 of the $C$ - $\beta$-sheet. This vacant position in the L-molecule is then occupied by residues $P_{7}-P_{2}$ of the reactive site loop of the I-molecule with these residues forming a $\beta$-strand, hydrogen-bonding to $\mathrm{s} 2 \mathrm{C}$ of the $\mathrm{L}$-molecule. This loop-C-sheet interaction suggests an alternative mechanism for serpin polymerization in addition to the previously favored loop-A-sheet hypothesis. The side chain of asparagine-187 that is mutated to aspartic acid in antithrombin Rouen-VI is indicated. The figure was produced using MOLSCRIPT (35).

at this site in antithrombin Rouen-VI was eight times slower than in native control antithrombin (Fig. 7). Half of the native control antithrombin was cleaved at $12 \mathrm{~min}$ (Fig. $7 \mathrm{~A}$ ), whereas it took $100 \mathrm{~min}$ for half of the antithrombin Rouen-VI to become cleaved (Fig. $7 \mathrm{~B}$ ). This indicated that the $\mathrm{P}_{4}-\mathrm{P}_{3}$ peptide bond was less accessible to the enzyme in the variant and together with the peptide insertion results indicates that the A-sheet in antithrombin Rouen-VI more readily allows incorporation of the reactive site loop.

\section{Discussion}

Antithrombin Rouen-VI is shown here to result from a point mutation giving a replacement of 187 asparagine by aspartate. The variant has an increased heparin affinity (Fig. 2) but retains near normal inhibitory activity (Table I), though this deteriorates slowly on storage at $4^{\circ} \mathrm{C}$ and more rapidly so on incubation at $37^{\circ} \mathrm{C}$ and markedly more so at $41^{\circ} \mathrm{C}$ (Fig. $3 \mathrm{E}$ ). This loss of inhibitory activity of the variant antithrombin is accompanied by the appearance of two conformational changes. One change is the formation of short chain polymers evident on both electrophoresis (Fig. 3, $C$ and $D$ ) and electron microscopy (Fig. 4). The second change occurs to the monomer and is accompanied by a loss of inhibitory activity and a characteristic anodal shift on electrophoresis (Fig. $3 \mathrm{D}$ ). On denaturing TUG gel electrophoresis (Fig. 5) the variant antithrombin is seen to have a decreased conformational stability. However, the new monomeric component that develops on prolonged storage or on incubation at $41^{\circ} \mathrm{C}$ is seen to have markedly increased folding stability, and sequencing showed only a single sequence representing the normal $\mathrm{NH}_{2}$ terminus and hence excluded the presence of loop-cleaved antithrombin. Taken together, these properties are characteristic of the induced L-form of antithrombin. This L-form has been shown (7) to have a structure analogous to that of latent PAI-1 (9) and for simplicity of notation it is in places referred to in this paper as latent antithrombin. The term $\mathrm{L}$-antithrombin ( $\mathrm{L}$ for locked) is more correct, even if less descriptive, as it is not possible to demonstrate the reversibility of the latency by de- and renaturation of antithrombin, as it is possible to do with PAI-1.

An indication of the mechanism likely involved in the conformational change of the Rouen variant to the L-form monomers and short chain polymers is provided by the recently completed $3 \AA$ structure of the crystals of a dimer of latent and native antithrombin of Wardell and colleagues $(7,13)$. The structure of the L-antithrombin (shown schematically in Fig. 1 $C$ ) has a similar folded reactive loop conformation to that of 

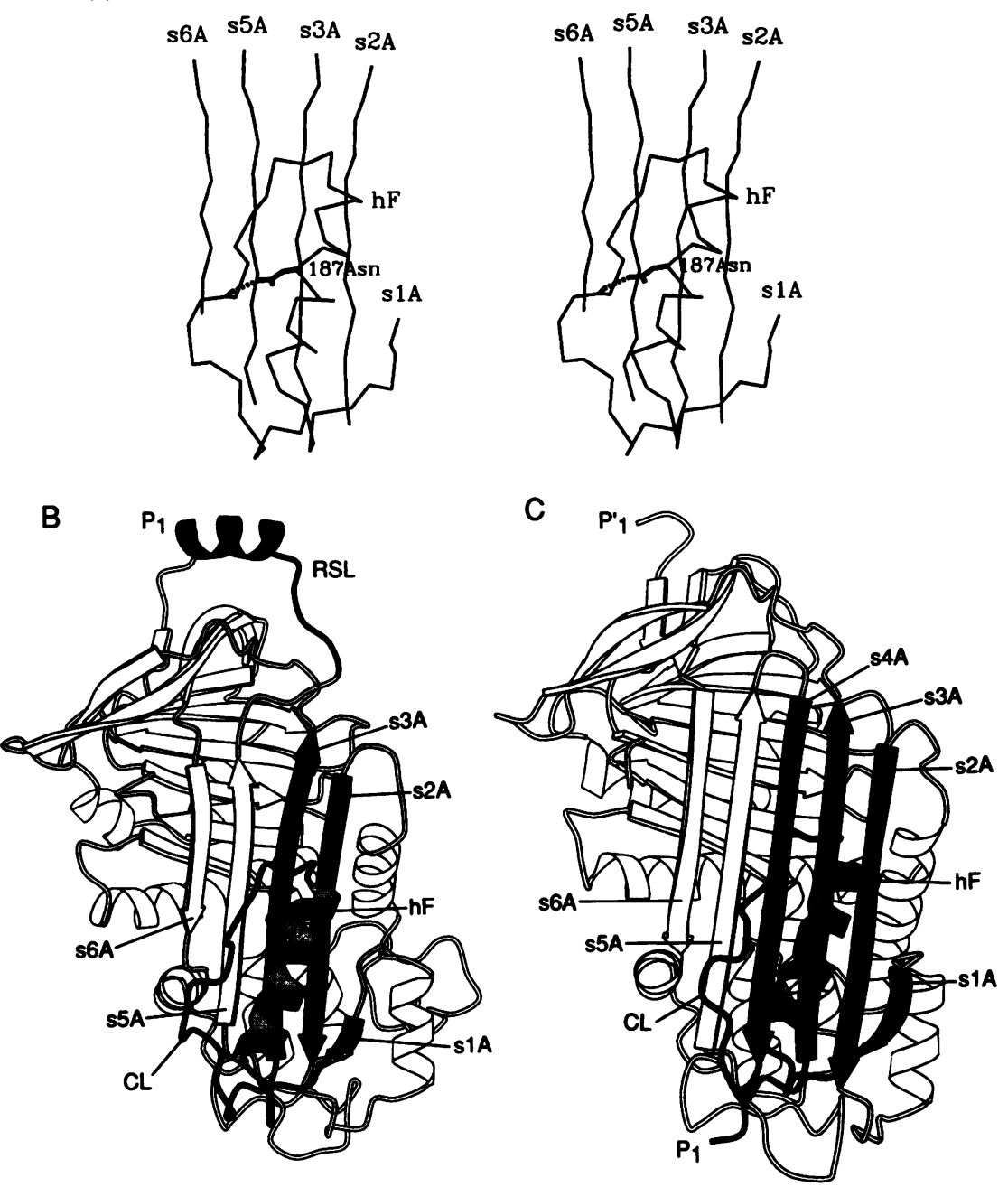

Figure 9. Serpin structural representations illustrating the association between the F-helix and the $\mathrm{A}-\beta$-sheet. $A$ is a stereo diagram of the $\mathrm{A}-\beta$ sheet (s1A, s2A, s3A, s5A, and s6A), the F-helix $(h F)$, and the loop that connects the two structural elements together in an intact antithrombin model based on the ovalbumin structure. The hydrogen bond between the highly conserved Asn187 in the F-helix and a carbonyl oxygen (Ile202 in antithrombin) in the connecting loop, which is present in all serpin crystal structures to date, is highlighted. In association with hydrophobic interactions between residues in s3A and the F-helix and between residues in s5A and the connecting loop, this hydrogen bond may be important in helping to keep the A- $\beta$-sheet closed between strands s3A and s5A in intact inhibitory serpins. This hydrogen bond cannot form in antithrombin Rouen-VI, seemingly allowing the A$\beta$-sheet to open more readily in this variant. $B$ and $C$ show diagrammatic representations of the structures of uncleaved ovalbumin and cleaved $\alpha_{1}$-antitrypsin, respectively, produced using MOLSCRIPT (35). The shaded portion represents the fragment which moves relative to the remainder of the molecule to accomodate the insertion of the reactive center loop (black in ovalbumin ) into the middle of the $\mathrm{A}-\beta$-sheet as strand s4A (black in $\alpha_{1}$-antitrypsin) after cleavage (28). $R S L$, reactive site loop; $C L$, connecting loop between the F-helix and s3A. latent PAI-1. Furthermore, the antithrombin dimer is formed by interaction of the reactive site loop of the active molecule of antithrombin (Fig. $1 \mathrm{~B}$ ) with the $\mathrm{C}$-sheet of the latent form (Fig. 8). It had been postulated previously (10) that loop-sheet polymerization occurred due to the insertion of the reactive loop of one molecule into the A-sheet of the next. The findings here would fit more readily with a $\mathrm{C}$-sheet linkage as seen in Fig. 8 and discussed in reference 7. The two mechanisms are not contradictory, as the trigger for $\mathrm{C}$-sheet bonding is likely to be an initial incorporation of the reactive center loop into the Asheet with an accompanying release of strand 1 of the $\mathrm{C}$-sheet. Thus in the Rouen variant, an increased accessibility of the Asheet for loop incorporation is likely to have two consequences. It will allow more ready formation of the completely incorporated L-form, as is observed. If this occurs in numbers of molecules at the same time, sequential $\mathrm{C}$-sheet linkage could occur to give polymer formation. The formation of the polymer would be expected to be terminated by a molecule that completely incorporates to give the L-conformation. This mechanism fits with the observation that antithrombin (which readily undergoes the L-transition) forms short dimer/trimer/tetramer oligomers, whereas $\alpha_{1}$-antitrypsin (which less readily gives full incorporation to the L-form) typically forms longer polymers of 10 or more molecules.
The mutation of 187 Asn $\rightarrow$ Asp has implications for the conformation of the underlying A-sheet as it involves a conserved asparagine that forms a key hydrogen bond in the Fhelix (Fig. $9 \mathrm{~A}$ ). The F-helix is involved with strands s1As3A in the sliding movement (28) that opens the A-sheet to allow the incorporation of strand s4A, shown schematically in Fig. 9, $B$ and $C$. In all known serpin crystal structures $(5,6$, 11, 29-32), asparagine-187 (corresponding to Asn-158 in $\alpha_{1^{-}}$ antitrypsin) forms a hydrogen bond to a carbonyl group in the peptide loop that connects the F-helix to strand $3 \mathrm{~A}$ (CL in Fig. 9). Amino acids in this peptide loop make a number of hydrophobic interactions with residues in strand $5 \mathrm{~A}$ of the Asheet, and therefore this loop will contribute to stabilizing the A-sheet in its closed five-stranded form. The replacement of asparagine- 187 by aspartate and the consequent loss of the amide nitrogen, as occurs in antithrombin Rouen-VI, will break this link between the F-helix and the connecting peptide loop, allowing movement of strands $1 \mathrm{~A}, 2 \mathrm{~A}$, and $3 \mathrm{~A}$ and an opening of the A-sheet between s3A and s5A. Supporting evidence of the opening of the A-sheet is shown by the more rapid insertion of the $\mathrm{P}_{14}-\mathrm{P}_{4}$ reactive site loop homologue peptide (Fig. 6) and evidence of the more ready incorporation of the loop by its changed accessibility to proteolytic attack (Fig. 7).

The thermolability of antithrombin Rouen-VI and its readi- 
ness to spontaneously undergo conformational changes to inactive forms provide a satisfying explanation for the clinical features associated with this variant. The incidence of thrombosis in affected individuals has been episodic, and in five of the six occurrences in the propositus' family thrombosis took place in association with an unrelated bout of fever. The inhibitory activity of freshly prepared antithrombin Rouen-VI toward thrombin is normal (Table I) but it rapidly decreases when exposed to a temperature of $41^{\circ} \mathrm{C}$ (Fig. $5 \mathrm{E}$ ). Furthermore, the antithrombin activity of whole plasma from heterozygous subjects decreases also upon incubation at $41^{\circ} \mathrm{C}$ to $<60 \%$ of normal activity. The clinical findings in the affected individuals fit well with the conclusion that antithrombin Rouen-VI functions adequately at $37^{\circ} \mathrm{C}$. However, when the temperature rises there will be accelerated formation of the L-state and loop-sheet polymers with loss of activity and hence risk of thrombosis. The consequences of polymerization will affect not only the activity of the plasma antithrombin but may result in decreased secretion of newly synthesized antithrombin from the liver. This is observed clinically with the analogous variants of $\alpha_{1}$-antitrypsin $(10,11)$ and, in cell cultures in vitro, with variants of $\mathrm{C}_{1}$-inhibitor (33). The double loss of both circulating inhibitor and of newly synthesized material may explain the unexpected severity of the thrombotic episodes associated with pyrexial infections in the Rouen-VI family.

\section{Acknowledgments}

We thank Dr. J.-M. Freyssinet for his generous gift of human thrombin; Dr. L. C. Packman for performing the protein sequence analysis; Dr. J. T. Finch for performing the electron microscopy; Mr. I. Jennings and Mr. R. Ludington for helping with the determination of antithrombin inhibitory activity in whole plasma; Dr. A. M. Lesk for help in producing Figs. 1 and $9 A$; and Dr. P. E. Stein for help in producing Fig. 8.

This work was supported in part by grants from the Wellcome Trust, the British Heart Foundation, the Medical Research Council, and the Foundation for the Study of Infant Deaths.

\section{References}

1. Olson, S. T., and I. Björk. 1992. Regulation of thrombin by antithrombin and heparin cofactor II. In Thrombin: Structure and Function. L. J. Berliner, editor. Plenum Publishing Corp., New York. 159-217.

2. Rosenberg, R. D., and P. S. Damus. 1973. The purification and mechanism of action of human antithrombin-heparin cofactor. J. Biol. Chem. 248:64906505 .

3. Huber, R., and R. W. Carrell. 1989. Implications of the three-dimensional structure of $\alpha_{1}$-antitrypsin for structure and function of serpins. Biochemistry. 28:8951-8966.

4. Carrell, R. W., D. Ll. Evans, and P. E. Stein. 1991. Mobile reactive centre of serpins and the control of thrombosis. Nature (Lond.). 353:576-578.

5. Stein, P. E., A. G. W. Leslie, J. T. Finch, W. G. Turnell, P. J. McLaughlin, and R. W. Carrell. 1990. Crystal structure of ovalbumin as a model for the reactive centre of serpins. Nature (Lond.). 347:99-102.

6. Schreuder, H. A., B. de Boer, R. Dijkema, J. Mulders, H. J. M. Theunissen, P. D. J. Grootenhuis, and W. G. J. Hol. 1994. The intact and cleaved human antithrombin III complex as a model for serpin-proteinase interactions. Nature Structural Biology 1:48-55.

7. Carrell, R. W., P. E. Stein, G. Fermi, and M. R. Wardell. 1994. Biological implications of a $3 \AA$ structure of dimeric antithrombin. Structure. 2:257-270.

8. Wei, A., H. Rubin, B. S. Cooperman, and D. W. Christianson. 1994. Crystal structure of an uncleaved serpin reveals the conformation of an inhibitory reactive loop. Nature Structural Biology 1:251-258.

9. Mottonen, J., A. Strand, J. Symersky, R. M. Sweet, D. E. Danley, K. F.
Geoghegan, R. D. Gerard, and E. J. Goldsmith. 1992. Structural basis of latency in plasminogen activator inhibitor-1. Nature (Lond.). 355:270-273.

10. Lomas, D. A., D. Ll. Evans, S. R. Stone, W.-S. W. Chang, and R. W. Carrell. 1993. Effect of the $\mathrm{Z}$ mutation on the physical and inhibitory properties of $\alpha_{1}$-antitrypsin. Biochemistry. 32:500-508.

11. Lomas, D. A., J. T. Finch, K. Seyama, T. Nukiwa, and R. W. Carrell. 1993. $\alpha_{1}$-Antitrypsin $S_{\text {iiyama }}\left(\operatorname{Ser}^{53} \rightarrow\right.$ Phe $)$. Further evidence for intracellular loopsheet polymerization. J. Biol. Chem. 268:15333-15335.

12. Aulak, K. S., E. Eldering, C. E. Hack, Y. P. T. Lubbers, R. A. Harrison, A. Mast, M. Cicardi, and A. E. Davis III. 1993. A hinge region mutation in Clinhibitor $\left(\mathrm{Ala}^{436} \rightarrow \mathrm{Thr}\right.$ ) results in nonsubstrate-like behavior and in polymerization of the molecule. J. Biol. Chem. 268:18088-18094.

13. Wardell, M. R., J.-P. Abrahams, D. Bruce, R. Skinner, and A. G. W Leslie. 1993. Crystallization and preliminary X-ray diffraction analysis of two conformations of intact human antithrombin. J. Mol. Biol. 234:1253-1258.

14. Laurell, C.-B. 1972. Electroimmuno assay. Scand. J. Clin. Lab. Invest. 29(Suppl. 124):21-37

15. Abildgaard, U., M. Lie, and O. R. Odegård. 1977. Antithrombin (heparin cofactor) assay with "new" chromogenic substrates (S-2238 and chromozym TH). Thromb. Res. 11:549-553.

16. Nordenman, B., C. Nyström, and I. Björk. 1977. The size and shape of human and bovine antithrombin III. Eur. J. Biochem. 78:195-203.

17. Rovelli, G., S. R. Stone, A. Guidolin, J. Sommer, and D. Monard. 1992. Characterization of the heparin-binding site of glia-derived nexin/protease nexin1. Biochemistry. 31:3542-3549.

18. Perry, D. J., P. L. Harper, S. Fairham, M. Daly, and R. W. Carrell. 1989. Antithrombin Cambridge, 384 Ala to Pro: a new variant identified using the polymerase chain reaction. FEBS (Fed. Eur. Biochem. Soc.) Lett. 254:174-176.

19. Cuatrecasas, P. 1970. Protein purification by affinity chromatography. Derivatizations of agarose and polyacrylamide beads. J. Biol. Chem. 245:30593065 .

20. Nordenman, B., and I. Björk. 1978. Binding of low-affinity and highaffinity heparin to antithrombin. Ultraviolet difference spectroscopy and circular dichroism studies. Biochemistry. 17:3339-3344.

21. Olson, S. T., K. R. Srinivasan, I. Björk, and J. D. Shore. 1981. Binding of high affinity heparin to antithrombin III. Stopped flow kinetic studies of the binding interaction. J. Biol. Chem. 256:11073-11079.

22. McKay, E. J. 1981. A simple two-step procedure for the isolation of antithrombin III from biological fluids. Thromb. Res. 21:375-382.

23. Laemmli, U. K. 1970. Cleavage of structural proteins during the assembly of the head of bacteriophage $\mathrm{T}_{4}$. Nature (Lond.). 227:680-685.

24. Goldenberg, D. P. 1989. Analysis of protein conformation by gel electrophoresis. In Protein Structure: A Practical Approach. T. E. Creighton, editor. IRL Press/Oxford, New York/Tokyo. 225-250.

25. Mast, A. E., J. J. Enghild, S. V. Pizzo, and G. Salvesen. 1991. Analysis of the plasma elimination kinetics and conformational stabilities of native, proteinase-complexed, and reactive site cleaved serpins: comparison of $\alpha_{1}$-proteinase inhibitor, $\alpha_{1}$-antichymotrypsin, antithrombin III, $\alpha_{2}$-antiplasmin, angiotensinogen, and ovalbumin. Biochemistry. 30:1723-1730.

26. Mast, A. E., J. J. Enghild, and G. Salvesen. 1992. Conformation of the reactive site loop of $\alpha_{1}$-proteinase inhibitor probed by limited proteolysis. Biochemistry. 31:2720-2728.

27. Carrell, R. W., and M. C. Owen. 1985. Plakalbumin, $\alpha_{1}$-antitrypsin, antithrombin and the mechanism of inflammatory thrombosis. Nature (Lond.) 317:730-732.

28. Stein, P., and C. Chothia. 1991. Serpin tertiary structure transformation. J. Mol. Biol. 221:615-621.

29. Loebermann, H., R. Tokuoka, J. Deisenhofer, and R. Huber. 1984. Human $\alpha_{1}$-proteinase inhibitor. Crystal structure analysis of two crystal modifications, molecular model and preliminary analysis of the implications for function. $J$. Mol. Biol. 177:531-556.

30. Wright, H. T., H. X. Qian, and R. Huber. 1990. Crystal structure of plakalbumin, a proteolytically nicked form of ovalbumin. Its relationship to the structure of cleaved $\alpha$-1-proteinase inhibitor. J. Mol. Biol. 213:513-528.

31. Baumann, U., R. Huber, W. Bode, D. Grosse, M. Lesjak, and C. B. Laurell. 1991. Crystal structure of cleaved human $\alpha_{1}$-antichymotrypsin at $2.7 \AA$ resolution and its comparison with other serpins. J. Mol. Biol. 218:595-606.

32. Mourey, L., J.-P. Samama, M. Delarue, M. Petitou, J. Choay, and D. Moras. 1993. Crystal structure of cleaved bovine antithrombin III at $3.2 \AA$ resolution. J. Mol. Biol. 232:223-241.

33. Verpy, E., E. Couture-Tosi, and M. Tosi. 1993. C $_{1}$-inhibitor mutations which affect intracellular transport and secretion in type I hereditary angioedema. Behring Inst. Mitt. 93:120-124.

34. Lesk, A. M., and K. D. Hardman. 1982. Computer-generated schematic diagrams of protein structures. Science (Wash. DC). 216:539-540.

35. Kraulis, P. J. 1991. MOLSCRIPT: a program to produce both detailed and schematic plots of protein structures. J. Appl. Cryst. 24:946-950. 